\title{
Diagnostic Tools for Evaluation of the Quality of the Anisotropic Conductive Adhesive Joints
}

\author{
Aleš Duraj ${ }^{1)}$ and Pavel Mach ${ }^{1)}$ \\ ${ }^{1)}$ Department of Electrotechnology, Faculty of Electrical Engineering \\ Czech Technical University, Prague 6, 166 27, Czech Republic \\ E-mail :duraja@centrum.cz
}

\begin{abstract}
Isotropic and anisotropic electrically conductive adhesives (ICAs and ACAs) are materials for special applications in electronic assembly. Quality of these adhesive joints is evaluated according of their electrical and mechanical properties. This paper is focused on evaluation of quality of Anisotropic Conductive Adhesives. Especially dependence of electrical resistance, noise and nonlinearity on bonding pressure is the main purpose of this research. Effect of curing (bonding) pressure of ACA was also analyzed with scanning electron microscope (SEM). Also influence of three different types of surface finishes $(\mathrm{Cu}, \mathrm{Cu}+\mathrm{Sn}, \mathrm{Cu}+\mathrm{Ni} / \mathrm{Au})$ of printed circuit boards has been examined and then evaluated effects on measured parameters.
\end{abstract}

\section{INTRODUCTION}

Conventional tin-lead soldering used in flip chip interconnections is incompatible with extremely fine pitch interconnection and is undesirable due to the toxic effects of lead. Anisotropic Conductive Adhesives (ACAs) and Anisotropic Conductive Films (ACFs) are mainly used in flip-chip assembly, chipon-film (COF), chip-on-glass (COG) or for flexible circuit assembly applications (chip-on-flex). So joining with anisotropic conductive adhesives and films is very fast and successfully spreading technology because of there is no requirement of applying additional underfill. ACFs are also extensively used for connection between PCB and LCD or liquid crystal module (LCM). The basic materials of the matrix are thermoset or thermoplastic (usually epoxy resin) with conductive filler - mainly balls with conductive layer (polymer $+\mathrm{Au}, \mathrm{Ni}+\mathrm{Au}$ ). These particles can be deformed between bonding electrodes during actual bonding, and this deformation increases the contact area between the conducting particles and bonding electrodes. Thus it lowers the interconnection resistance [1]. The main advantages of these types of conductive adhesives are anisotropic conductivity and suitability for fine-pitch connections. Disadvantage of ACAs and ACFs is a requirement of pressure during whole curing process. Pressure and heat are applied simultaneously so that the conductive particles can make contact with both bumps and substrate tracks and to be electrically connected. The degree of spread of the conductive particles owing the bonding pressure has a great influence on the contact resistance of the ACF joints. If the bonding pressure is too low, the particles may not be able to make contact between the connecting bumps and pads. Also degree of deformation of the conductive particles have a radical effect on quality and performance of interconnects [2]. If the applied pressure is too high, the metallic layer on particles will be burst and contact resistant increase. Deformation of conductive particles in ACAs owing to curing pressure is shown in Fig. 1.

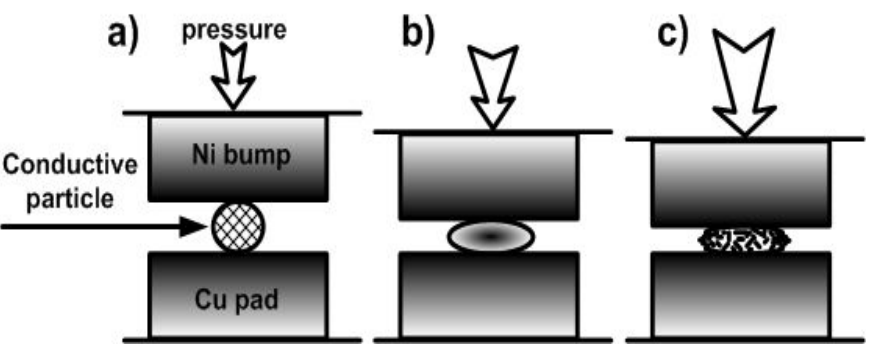

Fig. 1. Effect of curing pressure on shape of conductive particle in ACA a) minimal contact b) maximal contact c) too high pressure - breaking of particle.

In $\mathrm{ACF}$ and $\mathrm{ACA}$ bonding, temperature, pressure and time duration are the critical bonding parameters for optimal bonding conditions. So this work is mainly 
focused on an effect of curing pressure and the materials of testing board pads. The quality of bonding process is evaluated by measuring of basic electrical and also analyzed with SEM.

\section{EXPERIMENTS}

Tested joints have been prepared with assembly of SMD resistors (type 1206 0R0 from Microtech $\mathrm{GmbH})$ with special contacts metallization $(\mathrm{Cr} / \mathrm{Ni} / \mathrm{Ag})$ for adhesive connections. The SMD resistors are not usually assembled on PCBs with ACAs or ACFs, nevertheless for testing of influence of combination of curing pressure and pads materials are these components compliant.

Basic material of testing board (PCB) is common used FR4 and material of conductive paths is plated $\mathrm{Cu} 35 \mu \mathrm{m}$ foil. Three different types of surface finishes of conductive paths has been used $(35 \mu \mathrm{m} \mathrm{Cu}$, $35 \mu \mathrm{m} \mathrm{Cu}+\mathrm{Sn}$ (HASL), $35 \mu \mathrm{m} \mathrm{Cu}+5 \mu \mathrm{m} \mathrm{Ni}+1 \mu \mathrm{m}$ $\mathrm{Au}$ ). All analyses of the ACA adhesive joints have been carried out in a range of bonding pressure 0 to 10 MPa $(0-20 \mathrm{~N} / \mathrm{SMD})$ for investigation of influence curing pressure on quality of joints. ACA was cured with hot air under defined temperature and various pressure conditions.

There have been also prepared testing boards with low oxidation of $\mathrm{Cu}$ pads and paths. First set of testing boards (unassembled) were exposed in normal humidity ambient $\left(20^{\circ} \mathrm{C} / 25 \% \mathrm{RH}\right)$ and second set was put in to high humidity $\left(20^{\circ} \mathrm{C} / 95 \% \mathrm{RH}-500 \mathrm{hrs}\right.$.). This create an oxide compound $\mathrm{Cu}_{2} \mathrm{O}$ on surface of $\mathrm{Cu}$ pads and paths.

\begin{tabular}{|l|l|}
\hline \multicolumn{2}{|l|}{ LOCTITE 3447 - Anisotropic Conductive Adhesive } \\
\hline Chemical type & Epoxy \\
\hline Filler type & Ni filler (Au coated) \\
\hline Filler size & $7 \mu \mathrm{m}$ \\
\hline Curing temperature & $180{ }^{\circ} \mathrm{C}$ for 5 seconds \\
\hline Curing pressure & $5 \mathrm{MPa}-10 \mathrm{MPa}$ \\
\hline $\mathrm{T}_{\mathrm{g}}$ & $150{ }^{\circ} \mathrm{C}$ \\
\hline Tensile strength & $32 \mathrm{MPa}$ \\
\hline CTE & $55 \mathrm{ppm} / \mathrm{K}$ \\
\hline
\end{tabular}

Tab. 1. Tested Anisotropic Conductive Adhesive.

\subsection{Electrical resistance}

Electrical resistance is mostly measured parameter for its simplicity and high predicative rate for determination of quality of joints. Resistance of the joints has been measured with the LCR meter HP 4248. The samples have been contacted with fourpoint probe method. The resistance of single resistors has been measured $\left(R_{r}=15 \mathrm{~m} \Omega\right)$ and then the system SMD resistor +2 joints assembled on the board has been measured and single joint resistance $R_{S}$ evaluated.

From our measurements is clear that resistance is strongly dependent on curing pressure of ACAs. Small oxidation of $\mathrm{Cu}$ pads has an effect on resistance mainly under low values of curing pressure. Between recommended pressure $(5-10 \mathrm{MPa})$ there is influence of layer of $\mathrm{Cu}_{2} \mathrm{O}$ only $3 \%$ to $5 \%$ of resistance change. So evaluation of low changes in quality of adhesive joints with measurement of electrical resistance is not very advantageous because of low sensitivity. Detail of single joint resistance is depicted in Fig. 2.

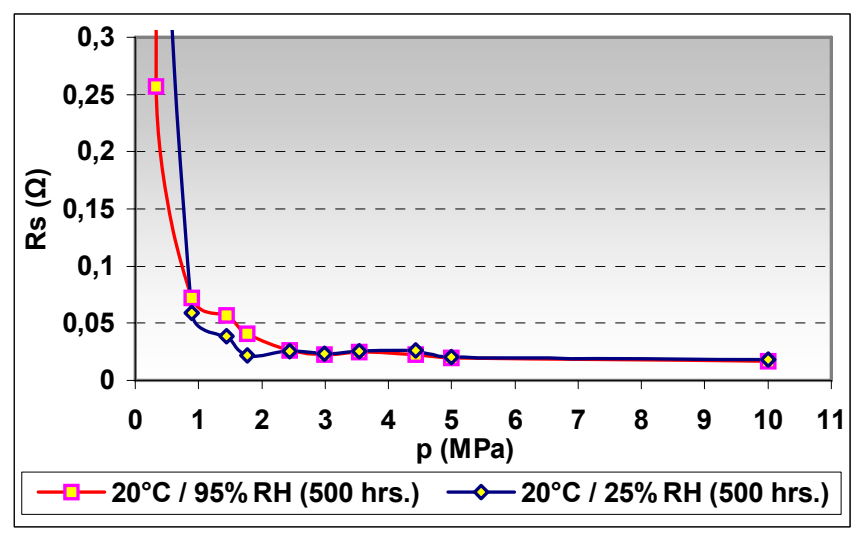

Fig. 2. Dependence of joint resistance Rs on curing pressure and oxidation of $\mathrm{Cu}$ paths.

Effect of various types of metallization of pads is shown in Fig. 3. Differences of joint resistance $R_{S}$ between three tested surface finishes are not too high throughout range of curing pressure. There is difference only about $18 \%$ between $\mathrm{Cu}+\mathrm{Sn}$ metallization (the lowest $\mathrm{R}_{\mathrm{S}}$ ) and $\mathrm{Cu}+\mathrm{Ni} / \mathrm{Au}$ metallization (the highest $\mathrm{R}_{\mathrm{S}}$ ) in a range of curing pressure $5-10 \mathrm{MPa}$. There is clear that measurement of resistance as a diagnostic tool of quality of joints is not very sensitive for small variances. 


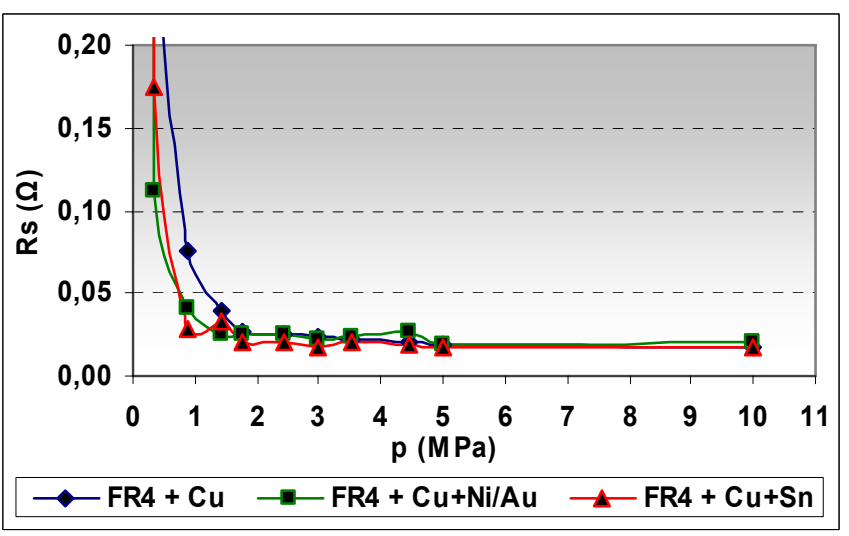

Fig. 3. Influence of curing pressure and material of pads on resistance of ACA joint.

\subsection{Nonlinearity of the $C$-V characteristics}

Nonlinearity of the current vs. voltage $(\mathrm{C}-\mathrm{V})$ characteristics of the joints has been measured by the method of measurement of the intermodulation distortion and evaluated with spectral analyzer unit HP 8560. Nonlinearity measurement was carried out over 2 joints and SMD resistor. Most frequently expression of nonlinearity of $\mathrm{C}-\mathrm{V}$ characteristics is with third harmonic index THI;

$$
T H I=20 \log \frac{U_{C}}{U_{1}^{n}}
$$

where $\mathrm{Uc} \sim \mathrm{U}_{3}$ (third harmonic signal- evaluated) and $\mathrm{U}_{1}$ is fundamental sine wave signal.

Influence of low oxidation of $\mathrm{Cu}$ pads on measured nonlinearity of $\mathrm{C}-\mathrm{V}$ characteristics of ACA joints is shown in Fig. 4. It is evident that when pressure is applied than the nonlinearity rapidly decreases and stabilizes at $5 \mathrm{MPa}$ pressure. This value of pressure is also recommended from the manufacturer of tested adhesive as the lowest pressure for electronic assembly. The values of nonlinearity are for high curing pressures very low but effect of oxidation is clear. This thin layer of oxide increase values of $U_{C}$ over $31 \%$ at $5 \mathrm{MPa}$ curing pressure, respectively over $6 \%$ at $10 \mathrm{MPa}$ in comparison with no-oxidized testing board. So measurement of nonlinearity is more sensitive for low changes of adhesive joints quality than common used evaluation of electrical resistance. Nevertheless disadvantage of this method is more sophisticate and also expensive measuring equipment.

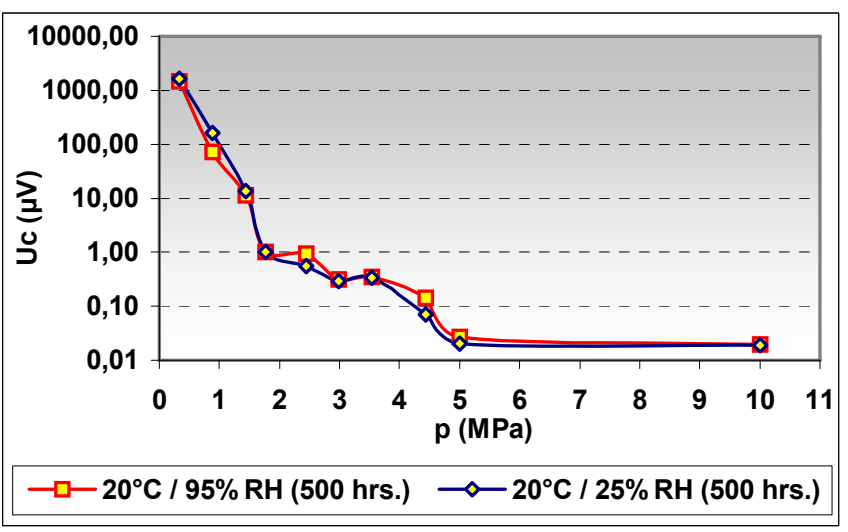

Fig. 4. Effect of curing pressure and oxidation of $\mathrm{Cu}$ pads on nonlinearity of ACA joints.

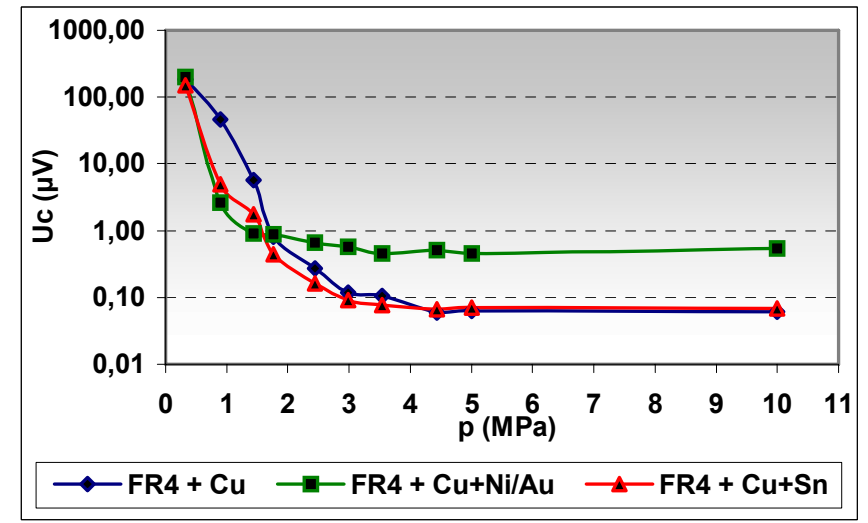

Fig. 5. Effect of curing pressure and pads metallization on nonlinearity of $\mathrm{C}-\mathrm{V}$ characteristic of ACA joints.

Different types of metallization have higher effect on nonlinearity of $\mathrm{C}-\mathrm{V}$ characteristic than on electrical resistance of ACA joints. This thesis is evident from graphs in Fig. 5. Effect of additional layers on $35 \mu \mathrm{m}$ thick $\mathrm{Cu}$ is mostly clear at $\mathrm{Cu}+\mathrm{Ni} / \mathrm{Au}$ metallization measured parameter $U_{C}$ is more than 10-times higher than at basic $\mathrm{Cu}$ pads without other layers. Electrolessdeposited $5 \mu \mathrm{m}$ thick layer of $\mathrm{Ni}$ and $1 \mu \mathrm{m}$ of $\mathrm{Au}$ on primary $\mathrm{Cu}$ pads and $\mathrm{Ni}$ conductive particles with $\mathrm{Au}$ conductive layer in ACA create several boundaries which can be registered with measurement of nonlinearity but not with measuring of electrical resistance. Values of nonlinearity for $\mathrm{Cu}$ and $\mathrm{Cu}+\mathrm{Sn}$ metallization are similar because there are probably intermetallic compounds $\left(\mathrm{Cu}_{3} \mathrm{Sn}\right.$ and $\left.\mathrm{Cu}_{6} \mathrm{Sn}_{5}\right)$ which have more linear $\mathrm{C}-\mathrm{V}$ characteristic than boundaryline. So measurement of nonlinearity of $\mathrm{C}-\mathrm{V}$ characteristics is very suitable diagnostic tool for evaluation of quality of ACA and ACF joints. 


\subsection{Electrical noise}

Total electrical noise ( $1 / \mathrm{f}$ noise) is combination of thermal noise and current noise $\mathrm{U}_{\mathrm{RMS}}$ (evaluated). $1 / \mathrm{f}$ noise in material structure is often a better diagnostic tool for degradation of components or connections than resistance measurements only. There are a few different methods for measurement of noise. In our case we used differential preamplifier + Princeton 124A Lock-In Amplifier for a measurement of noise signal and as DC supply has been used $12 \mathrm{~V}$ lead-acid battery. Measurement has been accomplished only for one frequency $\mathrm{f}=373 \mathrm{~Hz}$ and applied current through measured samples was kept below $400 \mathrm{~mA}$. Single joint evaluation of noise could not be carried out. So chain of 7 SMD resistors was measured and than current noise $\mathrm{U}_{\mathrm{RMS}}$ of $\mathrm{SMD}+2$ adhesive joints is evaluated with equation;

$$
U_{R M S}^{2}=\frac{\sqrt{U_{B}^{2}-U_{W B}^{2}}}{20 \sqrt{7}}
$$

where $U_{B}$ is measured signal (battery in circuit) and $\mathrm{U}_{\mathrm{WB}}$ is measured signal (without battery in circuit).

Influence of pads oxidation on current noise $\mathrm{U}_{\mathrm{RMS}}$ of tested ACA joints is depicted in Fig. 10. Zero curing pressure is like a measurement of open connection and is not interpreted. For low pressure $(<$ $4 \mathrm{MPa}$ ) there is almost no effect of oxidation. However above $5 \mathrm{MPa}$ there is growth of current noise about $80 \%$ for oxidized $\mathrm{Cu}$ pads. It is probably caused by increasing of deformation of conductive particles and by growing of connections between oxide layer and conductive layer $(\mathrm{Au})$ on Ni particles of ACA.

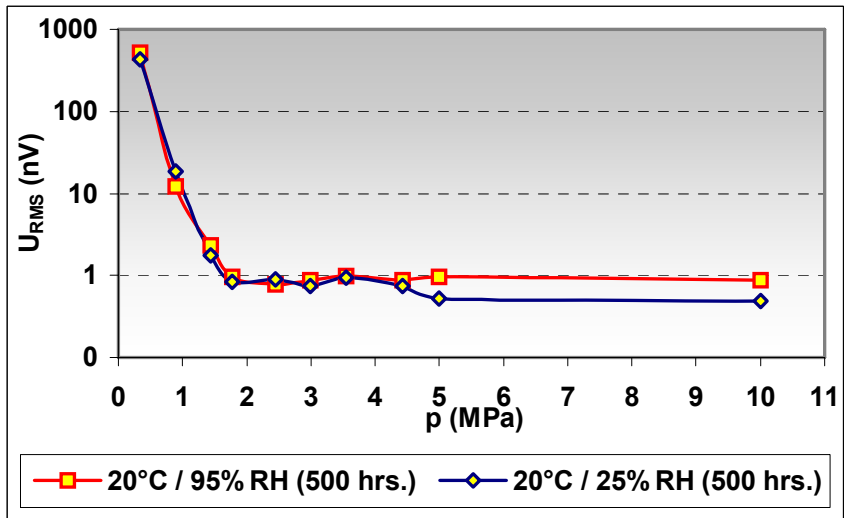

Fig. 6. Dependence of current noise $U_{R M S}$ on bonding pressure and pads oxidation.
Current noise has been also measured for two types of metallization of $\mathrm{Cu}$ pads and results are shown in Fig. 7. Differences of current noise $\mathrm{U}_{\mathrm{RMS}}$ between $\mathrm{Cu}$, $\mathrm{Cu}+\mathrm{Sn}$ and $\mathrm{Cu}+\mathrm{Ni} / \mathrm{Au}$ surfaces of testing board are very low ( $\pm 10 \%$ at 5-10 MPa) nevertheless this measurement is more sensitive than evaluation of contact resistance.

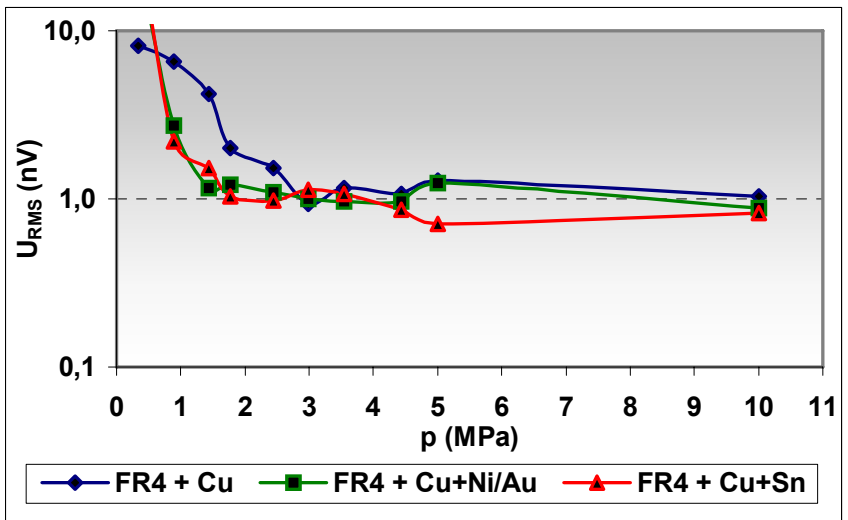

Fig. 7. Influence of bonding pressure of ACA and pads metallization on current noise $\mathrm{U}_{\mathrm{RMS}}$.

Disadvantage of measurement of current noise (1/f noise) is a high sensitivity to electrical dissolution and necessity to use proper shielding. Nevertheless from many studies and experiments is noise successfully used as a diagnostic tool for reliability assessment.

\subsection{Scanning electron microscope (SEM)}

The Scanning Electron Microscope (SEM) is a microscope that uses electrons to form an image. There are many advantages to using the SEM - has a large depth of field, which allows a large amount of the sample to be in focus at one time and also produces images of high resolution. These benefits makes the SEM one of the most heavily used instrument in research areas today. In our case the SEM can be usable for analysis of scratch pattern of ACA bonds. From measurement is clear that conductive particles create good electrical interconnection between lead of component and surface of substrate. Deformation of $\mathrm{Ni} / \mathrm{Au}$ conductive particle (20 $\mathrm{N}$ bonding pressure) is shown in Fig. 8. This deformation is low because of hard core (Ni) of this particle. Polymer particles with conductive layer $(\mathrm{Ni} / \mathrm{Au})$ can be deformed very well and therefore initial contact resistance of ACA joint is lower [3]. Comparison of SEM and optical microscopy photos is also purpose of next research. 


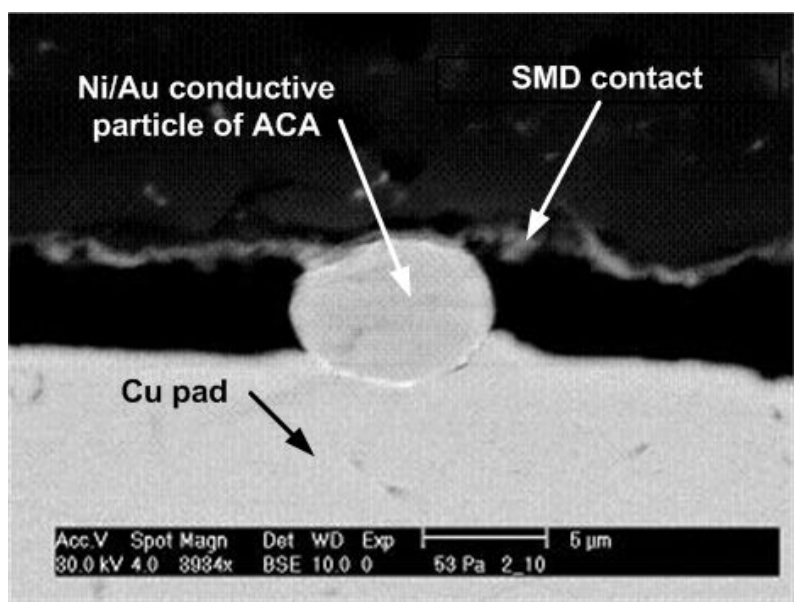

Fig. 8. SEM micrograph showing ACA interconnection through $\mathrm{Ni} / \mathrm{Au}$ conductive particle under $10 \mathrm{MPa}$ pressure

\section{Conclusions}

If zero bonding pressure is applied than the joint resistance $R_{S}$ is $5 \times 10^{5} \Omega$. For pressure 5-10 MPa (10 $20 \mathrm{~N} / \mathrm{SMD}$ ) electrical resistance decreases on 17 - 20 $\mathrm{m} \Omega$ for all types of pad metallization. Low oxidation $\left(\mathrm{CuO}_{2}\right)$ of $\mathrm{Cu}$ pads has only $3-5 \%$ of resistance change. So measurement of electrical resistance is not very sensitive for small changes in quality of joints. Whereas measuring of nonlinearity of $\mathrm{C}-\mathrm{V}$ characteristics is more than two-times sensitive (6$31 \%$ change of nonlinearity). Especially effect of additional layers (metallization) can be registered with measurement of nonlinearity nor evaluation of electrical resistance. Shift of current noise owing to oxidation of $\mathrm{Cu}$ pads was much greater than shift of electrical resistance. Disadvantage of measurement of current noise is a high sensitivity to electrical dissolution. Scanning electron microscope (SEM) has been used for analysis of interconnection between lead of SMD and $\mathrm{Cu}$ pads. Deformation process of conductive particle and substrate owing to bonding pressure has been observed and there has been found that $\mathrm{Ni} / \mathrm{Au}$ conductive particles in comparison with polymer particles deform very few. Other measurements and straining (impedance at high frequencies, dynamic mechanical load and high DC current load) will be done later for more complex analysis of ACA joints.

\section{ACKNOWLEDGMENTS}

The authors would like to acknowledge for financial support provided by research grant MSM no. 6840770021 - Diagnostic of Materials, Czech Republic.

\section{REFERENCES}

[1] Gautam S., S. Mridha, Tan Tin Chong, "Flip chip interconnect using anisotropic conductive adhesive", Journal of Materials Processing Technology, Vol. 8990, May 1999, pp. 484-490.

[2] Chan Y.C., Luk D.Y., "Effects of bonding parameters on the reliability performance of anisotropic conductive adhesive interconnects for flip-chip-on-flex packages assembly, II. Different bonding pressure", Microelectronics Reliability, Vol. 42, Issue 8, August 2002, pp. 1195-1204.

[3] Yin C.Y., Alam M.O., Chan Y. C., "The effect of reflow process on the contact resistance and reliability of anisotropic conductive film interconnection for flip chip on flex applications", Microelectronics Reliability, Vol. 43, Issue 4, April 2004, pp. 625-633.

[4] Chiu Y.W., Chan Y.C., Lui S.M., "Study of shortcircuiting between adjacent joints under electric field effects in fine pitch anisotropic conductive adhesive interconnects", Microelectronics Reliability, Vol. 42, Issue 12, December 2002, pp. 1945-1951.

[5] Liu J., "On the Failure Mechanism of Anisotropically Conductive Adhesive Joints on Copper metallization", International Journal of Adhesion and Adhesives, Vol. 16, Issue 4, 1996, pp. 285-287. 